\title{
Obsessive-Compulsive Disorder in Children and Adolescents
}

\author{
Susanne Walitza, Siebke Melfsen, Thomas Jans, Henrike Zellmann, \\ Christoph Wewetzer, and Andreas Warnke
}

\section{SUMMARY}

Background: Early-onset obsessive-compulsive disorder (OCD) is one of the more common mental illnesses of children and adolescents, with prevalence of $1 \%$ to $3 \%$. Its manifestations often lead to severe impairment and to conflict in the family. In this review, we summarize the manifestations, comorbidity, pathophysiology, and course of this disease as well as current modes of diagnosis and treatment.

Methods: We selectively review the relevant literature and the German-language guidelines for the diagnosis and treatment of mental illnesses in children and adolescents.

Results: Obsessive-compulsive manifestations are of many types and cause severe impairment. Comorbid mental disturbances are present in as many as $70 \%$ of patients. The disease takes a chronic course in more than $40 \%$ of patients. Cognitive behavioral therapy is the treatment of first choice, followed by combination pharmacotherapy including selective serotonin reuptake inhibitors (SSRI) and then by SSRI alone.

Conclusion: OCD often begins in childhood or adolescence. There are empirically based neurobiological and cognitivebehavioral models of its pathophysiology. Multiaxial diagnostic evaluation permits early diagnosis. Behavioral therapy and medications are highly effective treatments, but the disorder nonetheless takes a chronic course in a large percentage of patients.

\section{- Cite this as:}

Walitza S, Melfsen S, Jans T, Zellmann H, Wewetzer C, Warnke A: Obsessive-compulsive disorder in children and adolescents. Dtsch Arztebl Int 2011; 108(11): 173-9. DOI: 10.3238/arztebl.2011.0173
Zentrum für Kinder- und Jugendpsychiatrie, Universität Zürich: Prof. Dr. med. Walitza, Dr. Melfsen

Klinik für Kinder- und Jugendpsychiatrie, Psychosomatik und Psychotherapie der Universität Würzburg: Dr. Dipl.-Psych. Jans, Zellmann, Dr. Melfsen, Prof. Dr. med. Andreas Warnke

Klinik für Kinder- und Jugendpsychiatrie, Kinderkrankenhaus (Riehl), Köln: Prof. Dr. med. Christoph Wewetzer
O bsessive-compulsive disorder is common not just in adults, but also in children and adolescents. It impairs the quality of life of the affected young people but is often diagnosed only after a delay. This article is based on a selective review of the relevant literature retrieved by a PubMed search, with additional consideration of the German-language guidelines for the diagnosis and treatment of obsessive-compulsive disorder (1). In it, we provide an overview of the clinical features, comorbidities, and course of early-onset obsessive-compulsive disorder. We discuss the current explanatory approaches and the available modalities of diagnosis and treatment.

\section{Definition and clinical features}

Obsessive-compulsive disorder is a complex pathological entity that can take on a wide variety of forms. The essential clinical features for its diagnosis in children and adolescents are, according to the ICD-10 (Box 1), the same as those in adults:

- The patient must suffer from obsessions and/or compulsions, i.e., thoughts and/or behavioral impulses. However recognized as own thoughts, they are involuntary and often repugnant in the patient's own mind.

- At least one of these obsessions and/or compulsions must be resisted.

- The patient does not perceive the manifestations of the disorder as being pleasurable.

- The obsessions and/or compulsions occur repetitively; the patient is troubled by them and is markedly impaired by them.

According to the Diagnostic and Statistical Manual of Mental Disorders (DSM-IV), the diagnosis is permissible even in children who lack insight into the inappropriateness of their obsessions and/or compulsions and do not put up any resistance to them (2). A subclassification of the disorder, depending on the degree of insight and delusional features of the obsessions and compulsions, is planned for the coming DSM-V. Children and adolescents often manifest multiple obsessive-compulsive features at the same time. Geller et al. found that the commonest types of obsessions and compulsions in this age group had to do with cleaning ( $32 \%$ to $87 \%$ ), followed by repetition, checking, and aggressive thoughts (3). In the authors' own study, the commonest types had to do with cleaning $(60 \%)$ and 
BOX 1

\section{ICD-10 criteria for obsessive-compulsive disorder (age-independent)*}

For a definite diagnosis, obsessional symptoms or compulsive acts, or both, must be present on most days for at least 2 successive weeks and be a source of distress or interference with activities.

The obsessional symptoms should have the following characteristics:

- They are acknowledged as originating in the mind of the patient, and are not imposed by outside persons or influences.

- The subject tries to resist them (but if very long-standing, resistance to some obsessions or compulsions may be minimal). At least one obsession or compulsion must be present which is unsuccessfully resisted.

- Carrying out the obsessive thought or compulsive act is not in itself pleasurable. (This should be distinguished from the temporary relief of tension or anxiety).

- The thoughts, images, or impulses must be unpleasantly repetitive.

*ICD-10 Classification of Mental and Behavioral Disorders, World Health Organization, Geneva, 1992.

\section{BOX 2}

\section{Diagnostic techniques for the evaluation of obsess- ive-compulsive disorder in children and adolescents}

- Clinical interview for basic diangostic assessment.

- Hamburg Obsession-Compulsion Inventory ( $\mathrm{HOCl})$ : this is a self-assessment instrument that can be used by adolescents (e7, e18).

- Hamburg Obsession-Compulsion Inventory-Short Form (HOCl-SF), (e19).

- Leyton Obsessional Inventory: this is a self-assessment instrument that is also available in a version for children (e20).

- Children's Yale-Brown Obsessive Compulsive Scale (CY-BOCS): this is a semistructured interview for children and adolescents corresponding to the Y-BOCS for adults (e21).
$3 \%(9,10)$. According to the US National Comorbidity Survey Replication (NCS-R) by Kessler et al., about $20 \%$ of all affected persons in the USA suffer from manifestations of the disorder at age 10 or even earlier $(11,12)$. Delorme et al. consider the disorder to have a bimodal age distribution, with a first peak at age 11 and a second one in early adulthood (13). Among the affected children, there seem to be more boys than girls, in a ratio of about $3: 2$, although this has not been confirmed in all of the relevant studies $(14,15)$. From adolescence onward, the prevalence in boys and girls is the same.

\section{Diagnosis and differential diagnosis}

In children and adolescents, as in adults, obsessivecompulsive disorder is often long overlooked by others and/or hidden by the sufferer. In our own studies, treatment was begun at an average age of 13 years; this, in turn, was an average of two years after the disease manifestations began (16). When taking the history and conducting an exploratory interview, the examiner should carefully search for the core manifestations, possible comorbidities, and psychosocial impairments that may arise as the patient develops and the illness progresses. Within the framework of the multiaxial psychiatric diagnostic approach that should be used for all patients, standardized psychodiagnostic procedures are now available for the assessment of the specific manifestations of obsessive-compulsive disorder (1) (Box 2).

Behavioral analysis for the planning and provision of treatment comprises the following elements:

- The manifestations and severity of the patient's obsessions and/or compulsions

- Internal and external precipitating factors

- Fears or expectations about what would happen if the compulsive rituals were not performed

- Defense mechanisms (what types of behavior does the patient already use to help himself or herself?)

- Reactions of family members and other persons in a close relationship with the patient (involvement; protective resources, reinforcing influences).

The differential diagnosis involves distinguishing obsessive-compulsive disorder from a number of other entities (Box 3).

\section{Comorbidities}

Comorbid disorders are reportedly present in $68 \%$ to $100 \%$ of cases and are thus the rule rather than the exception (4). The most common types of comorbidity are anxiety disorders, tic disorders, attention deficit/hyperactivity disorder (ADHD), and personality disorders, which become more common with advancing age. Recent studies have revealed higher rates of externalizing behavioral disorders (ADHD, conduct disorders) $(17,18)$. The more severe the obsessive-compulsive disorder, the more likely it is that there will be one or more comorbid disorders $(4,19$, 20). 


\section{Possible differential diagnoses of obsessive-compulsive disorder in children and adolescents}

- Subclinical compulsive behaviors: these are defined as behaviors lying within the normal range that do not impair the child's development.

- Rituals that help the child to process experiences and obtain security: these are calming rather than stress-inducing behaviors.

- Compulsive behavior in the setting of medical illness: this does not have the same functional significance as compulsive behavior in OCD.

- Obsessive thoughts arising in the setting of another Axis I disorder, such as a phobia, eating disorder, or depression: the content of such thoughts is related exclusively to central aspects of the Axis I disorder. Depressive brooding, for example, is egosyntonic.

- Obsessive-compulsive personality disorder: this is experienced as egosyntonic, and the typical obsessions and compulsions of OCD are absent.

- Schizophrenia and delusional disorders: the distinguishing features of $O C D$ are egodystonia and preserved reality testing.

- Autistic disorders: obsessive-compulsive manifestations in autistic persons are generally experienced as egosyntonic and do not cause distress.

- Obsessive-compulsive spectrum disorders: obsessions and compulsions can be difficult to distinguish from hypochondriasis, dysmorphophobia, and impulse-control disorders.

- Apparently compulsive tics (e.g., in complex motor tic disorders): tics and compulsions are sometimes very hard to tell apart. Tics are characterized by bodily tension; the behaviors are not goal-directed, nor are they connected with fears or anxieties, and it is difficult or impossible to suppress them voluntarily.

- Stereotypic behaviors, e.g., in autistic or mentally retarded persons: these are experienced as pleasurable by the affected persons, as they offer a means of self-stimulation during sensory deprivation, or, alternatively, a means of distraction during sensory overload.

- Rigidity in ADHD: this can be regarded as an attempt to regain control over the inner chaos of one's own mental world.

\section{The course of early-onset obsessive-compulsive disorder}

Studies of the course of obsessive-compulsive disorder reveal that it often becomes a chronic condition. In a meta-analysis of (mostly American) studies on the long-term course of obsessive-compulsive disorder in children and adolescents, involving a total of 521 patients, Stewart et al. found a mean persistence rate of $41 \%$ for the florid disorder, and one of $60 \%$ when subclinical manifestations were taken into account (21). The available studies from Europe to date include a Danish retrospective study of disease course by Thomsen et al. and a study from Würzburg, Germany, by Wewetzer et al. $(22,23)$. In the Danish study, only $13(28 \%)$ of the 47 patients were in remission with respect to their obsessive-compulsive manifestations after a mean follow-up interval of 15 years (22). Wewetzer et al. arrived at similar findings after more than 11 years of follow-up (23): $70 \%$ of the original patient group still suffered from mental disorders at the end of this interval, and $36 \%$ of them had persistent obsessive-compulsive disorder. Another, more recent study from Würzburg is the first to assess the middleto long-term course of obsessive-compulsive disorder prospectively. Patients' age of onset was 11.3 years; just under six years after baseline assessment, the findings were nearly identical to those of the previous study $(24,25)$. In both of the Würzburg studies, however, the severity of the disorder, measured with the Y-BOCS, was significantly lower immediately after the initial treatment, and also at the time of follow-up $(23,24)$.
A recent prospective study showed that ADHD, when present as a comorbid disorder, is associated with more severe obsessive-compulsive disorder and a less favorable course (20). The few studies performed to date on the course of early-onset obsessive-compulsive disorder have shown that these patients have their most severe adaptive disturbances in the areas of social integration, age-appropriate development of independence from the family, and relationships (25, e1, e2). Early initiation of treatment, and the continuation of treatment once it is initiated, are associated with better outcomes $(20,25)$. It is, therefore, all the more important to diagnose obsessive-compulsive disorder early, as appropriate treatment improves the prognosis in addition to relieving the patient's current symptoms (Box 3).

\section{Etiology}

There are both neurobiological and metacognitivebehavioral findings and models pertaining to the causation of obsessive-compulsive disorder.

\section{Neurobiological approaches}

First-degree relatives of children and adolescents with obsessive-compulsive disorder are 3 to 12 times more likely to also have the disorder than the general population. The earlier the age of onset, the more frequently first-degree relatives are affected (e3). Twin studies show somewhat greater heritability of obsessivecompulsive symptoms in children $(0.45 \%$ to $0.65 \%)$ than in adults $(0.27 \%$ to $0.47 \%)(\mathrm{e} 4)$. Thus, the studies reveal a strong influence of genetic factors in the 


\section{GASE ILLUSTRATION}

A 10-year-old girl was admitted to the inpatient child and adolescent psychiatry ward on her parents' referral. She said she had begun blowing in the air after her grandfather's death, because she was not permitted to think about him when away from home. Any thoughts that she might have about her family when she was in other surroundings had to be "blown away." Later, she had to wash her hands after touching any persons outside her family that she didn't like, or even anything belonging to such a person. By now, she no longer needed to wash her hands and could just rub them. She explained that she did this, not to rub off actual dirt, but to rub off "the dirt you can't see," i.e., the strangeness of the people and things involved, which "grossed her out." Her parents related that she had lost many friends through these behaviors, and that her rituals also interfered with her schoolwork, causing low grades.

\section{Treatment:}

The following treatment plan was developed:

- Education of the patient and her parents about obsessive-compulsive disorder.

- Confrontational exercises with response prevention, e.g., touching "gross" objects and then not being able to rub off the supposed contamination.

- Discussion with the parents of ways to foster their daughter's autonomy.

- Social competence exercises to enable her to express her desires, aggressive thoughts, etc., in a situationally appropriate way.

\section{Course:}

The treatment outlined above brought about marked, but incomplete, improvement of this patient's obsessions and compulsions. The long duration of the illness until it was diagnosed and its severity on presentation were unfavorable prognostic factors. episodes. Snider et al. were the first to demonstrate the efficacy of antibiotic prophylaxis (e7, e8), which, however, is not routinely given in clinical practice.

\section{The cause of dysfunctional interpretative patterns}

According to metacognitive-behavioral findings and models, obsessive-compulsive disorders are due to the dysfunctional interpretative patterns employed by patients in response to intrusive negative thoughts that are actually normal (e9). Such patterns (e9, e10) lead, for example, to heightened perceptions of danger and personal responsibility, and to the subjective urgency of putting an end to troubling thoughts through aversive behavior. The patient's attempts to avoid thinking intrusive thoughts, or to suppress them, have the opposite effect, as they only heighten the patient's preoccupation with these thoughts. Short-term relief reinforces the behavior and lends greater subjective importance to the intrusive thoughts, so that the patient's continuous preoccupation with them becomes further stabilized. The affected individual is now trapped in a vicious circle of intrusive thoughts and attempts to resist them, or to neutralize them with compulsive behaviors. The cognitive model has not been studied as intensively in children and adolescents as it has in adults.

Persons in the child or adolescent patient's near environment, particularly parents, very often participate in the compulsive behavior, e.g., by repeatedly answering the questions of children who have a questioning/checking compulsion or by giving free rein to a repetitive washing compulsion. They may do so in order to avoid the aggressive reactions that commonly result when they try to put an end to the compulsive behavior by using parental discipline. In this way, they unintentionally maintain the vicious circle.

causation of early-onset obsessive-compulsive disorder (e3). On the other hand, the later the disease arises, the larger the role played by environmental conditions and traumata. Pertinent neuroimaging studies, along with neuropsychological findings indicating executive dysfunction (e.g., impaired reaction suppression and poor performance of planning tasks), suggest a disturbance of information processing in cortico-striatothalamo-cortical circuits. The reported benefit of treatment with deep brain stimulation (DBS) lend additional support to this hypothesis (e5).

\section{Obsessive-compulsive manifestations due to infectious dis- eases}

Obsessive-compulsive manifestations arising in the setting of infection with beta-hemolytic streptococci are subsumed under the acronymic heading "PANDAS" (pediatric autoimmune neuropsychiatric disorders associated with streptococcal infections). The pathophysiological mechanism seems to be a crossreaction in which antibodies primarily directed against group A beta-hemolytic streptococci react with the basal ganglia as well. The prevalence of PANDAS is unknown (e6). The manifestations arise suddenly, are often very severe, and regress between

\section{Psychotherapy}

The findings of a meta-analysis of all of the randomized controlled trials and open trials of cognitive behavioral therapy (CBT) that have been performed to date (e11) indicate that this type of treatment is highly effective (mean effect size, 1.55). The mean effect size of individual CBT was nearly as high as that of CBT with greater involvement of the family (1.77 and 1.88, respectively). Behavioral therapy (BT) consisting of exposure and response prevention has been found to be very effective: The patient exposes himself or herself to situations and obsessive thoughts that provoke anxiety, and their passive or active avoidance through neutralizing compulsive behaviors is prevented. The patient learns that the unpleasant emotions evoked in this way become progressively weaker and can ultimately be handled without any compulsive behavior. Real exposures are preferable to imagined ones; for some types of obsession/compulsion, additional imagination exercises are needed. BT should generally begin with situations of less than maximal severity in order not to bring out avoidant behavior. The initial situation 
should be chosen so that it can be created in controlled fashion in a familiar therapeutic setting that provides the patient with a degree of emotional security; it should also be of practical relevance to the patient. A cautious, graduated approach works just as well as a rapid, flooding approach. Children and adolescents generally prefer a less stressful, stepwise approach in which the intensity of the precipitating factor is gradually increased, even though this takes somewhat longer. The objective is a marked diminution of agitation or tension, down to a level that the child or adolescent patient can cope with without having to perform the compulsive behavior, followed by a generalization of the progress that has been achieved to the setting of the patient's everyday life. Psychoeducation of the parents is necessary as well.

Treatment by exposure can also be performed when the problem consists purely of obsessive thoughts, without any accompanying compulsive behavior. A distinction should be drawn between the intrusive thoughts and the neutralizing thoughts that arise in response to them. The goal of exposure is to provoke the intrusive thoughts; this can be done by administering external stimuli associated with them, or by describing them out loud on an audio recording and then playing the recording back. The neutralizing thoughts must not be allowed to arise during the exposure. One can ensure this, for example, by administering the exposure continuously, so that there is no time for "neutralization" to occur. In CBT, special attention is paid to the therapeutic relationship, the elucidation of the patient's motivation and the goals of treatment, and the functional role of obsessions and compulsions. Improvement after behavioral therapy seems to be stable in the long term: patients examined 3 years after treatment were even found to have a further, mild improvement of their symptoms (e12).

\section{Pharmacotherapy}

Selective serotonin reuptake inhibitors (SSRIs) are the drugs of first choice for children and adolescents with obsessive-compulsive disorder because they are both highly effective and well tolerated. Geller et al. performed a meta-analysis of 12 randomized, doubleblind, placebo-controlled studies of the effects of SSRIs and clomipramine (a tricyclic antidepressant) that involved a total of 1044 children and adolescents (e13). The pooled effect strength of SSRIs and clomipramine in comparison to placebo was determined to be 0.46 . Thus, the effect of these drugs was highly statistically significant, but only moderately strong, in fact weaker than that of behavioral therapy. Later studies, however, revealed stronger effects for both behavioral therapy and medication. Clomipramine was found to be the most effective drug in children and adolescents, as it is in adults. In Germany, clomipramine is approved for the treatment of enuresis, but not of obsessive-compulsive disorder, in children aged 5 years or older. Among the SSRI's, fluvoxamine is approved in
Germany for the treatment of obsessive-compulsive disorder in children aged 8 or older. The SSRI's do not differ from each other in their efficacy at improving the manifestations of the disease. The recommended doses for children and adolescents largely correspond to those for adults and are higher than the recommended doses of the same medications in the treatment of depressive disorders (for more on this topic, cf. Gerlach et al., 2009) (e14). The authors recommend therapeutic drug monitoring in children. Even though clomipramine is highly effective, it also has pronounced adverse effects and is therefore a third-choice drug. When either an SSRI or clomipramine is given, the beneficial effect should be expected to set in only after 4 to 10 weeks of treatment, and thus the effect should only be judged after 8 to 12 weeks have elapsed. If one SSRI should prove ineffective, another SSRI should be tried next; if the disease manifestations do not improve in response to the second SSRI either, one can consider adding an atypical neuroleptic drug, particularly if the patient suffers from a comorbid tic disorder. When switching drugs or giving combination therapy, one should keep in mind that SSRIs differ markedly from one another in pharmacokinetics (e15). Pharmacotherapy should be planned for the long term; attempts to taper and discontinue the drug(s) should always be carried out very slowly and no sooner than 6 months after the start of treatment, even if the initial treatment has been highly successful. Studies of the effects of CBT, medications, and combination therapy compared to placebo have shown that CBT is superior to the other options, but that the best effect of all can be obtained through a combination of CBT with medications [see e.g. the Pediatric OCD Treatment Study, POTS, (2004) (e16)].

\section{Treatment recommendations and future prospects}

Eight studies involving a total of 343 children and adolescents with obsessive-compulsive disorder who were treated with behavioral therapy (BT with exposure) or cognitive behavioral therapy (CBT with exposure and cognitive elements) were reviewed in a Cochrane analysis (e17). Separate analysis of BT and CBT was not possible, so the two together were compared to pharmacotherapy and combination therapy. $\mathrm{BT} / \mathrm{CBT}$ was found to be just as effective as treatment with an SSRI alone, and limited evidence was found for an even better effect from BT/CBT combined with medication. The drop-out rate was lower with BT/ CBT than with medication. The authors of the Cochrane analysis concluded that the data did not support any particular recommendation for which of the two, $\mathrm{BT} / \mathrm{CBT}$ or medication, should be given first. In view of the demonstrated and lasting effectiveness of behavioral therapy (i.e., BT or CBT), the current German-language guidelines recommend using these methods first to treat obsessive-compulsive disorder in childhood. For patients with longstanding, intractable manifestations of obsessive-compulsive disorder 
that continue well into adulthood, studies have shown that deep brain stimulation can be an effective treatment. This mode of treatment is not currently under discussion for children and adolescents. Further treatment options would be desirable for patients whose illness takes a particularly long, severe, and intractable course.

\section{Overview}

Obsessive-compulsive disorder is common but often diagnosed late in children and adolescents, just as in adults. Standardized diagnostic techniques are available. Possible comorbidities should be considered. Improvement can be achieved with behavioral therapy, e.g., exposure and response prevention, either alone or in combination with SSRI. The authors' findings point to the importance of treating obsessive-compulsive disorder early. As this illness tends to become chronic, it seems wise for all patients to undergo psychotherapy (perhaps at low frequency), alone or in combination with medications, once the initial phase of intensive treatment has been completed, even if it has been highly successful.

\section{KEY MESSAGES}

- Obsessive-compulsive disorder is common among children and adolescents and causes marked distress.

- Psychological, neurobiological, and genetic factors participate in its causation.

- The treatment of choice is exposure with response prevention, potentially supplemented by cognitive interventions and involvement of the patient's family.

- The SSRI are the drugs of first choice.

- The sooner treatment is begun, the more favorable the course.

\section{Conflict of interest statement}

Prof. Walitza has received lecture honoraria from Janssen Cilag and AstraZeneca.

Prof. Warnke cooperates in research and lecture activities with Medice, Novartis, Lilly, Janssen-Cilag, AstraZeneca and Shire.

PD Melfsen, Dr. Zellmann, Dr. Jans, and Prof. Wewetzer state that they have no conflict of interest as defined by the guidelines of the International Committee of Medical Journal Editors.

Manuscript submitted on 3 December 2009, revised version accepted on 16 June 2010

Translated from the original German by Ethan Taub, M.D.

\section{REFERENCES}

1. Wewetzer C, Walitza S, Reizle K: Zwangsstörungen. In: Deutsche Gesellschaft für Kinder- und Jugendpsychiatrie, Psychosomatik und Psychotherapie, Bundesarbeitsgemeinschaft Leitender Klinikärzte für Kinder- und Jugendpsychiatrie, Psychosomatik und Psychotherapie und Berufsverband der Ärzte für Kinder- und Jugendpsychiatrie, Psychosomatik und Psychotherapie eds.: Leitlinien zur Diagnostik und Therapie von psychischen Störungen im Säuglings-, Kindes- und Jugendalter. 3. überarbeitete und erweitere Auflage. Köln: Deutscher Ärzte-Verlag 2007: 73-87.
2. Sass H, Wittchen HU, Zaudig M, Houben I: Diagnostisches und Statistisches Manual Psychischer Störungen DSM-IV. 4. Auflage Göttingen: Hogrefe; 2003: 1001.

3. Geller DA, Biederman J, Jones J, Shapiro S, Schwartz S, Park KS: Obsessive-compulsive disorder in children and adolescents: a review. Harv Rev Psychiatry 1998; 5: 260-73

4. Jans T, Wewetzer C, Klampfl K, et al: Phänomenologie und Komorbidität der Zwangsstörung bei Kindern und Jugendlichen. Z Kinder Jugendpsychiatr Psychother 2007; 35: 41-50.

5. Leckman JF, Zhang H, Alsobrook JP, Pauls DL: Symptom dimensions in obsessive-compulsive disorder: toward quantitative phenotypes. Am J Med Genet 2001; 105: 28-30.

6. Goodman WK, Price LH, Rasmussen SA, et al: The Yale-Brown Obsessive Compulsive Scale. II. Validity. Arch Gen Psychiatry 1989; 46: 1012-6.

7. Goodman WK, Price LH, Rasmussen SA, et al: The Yale-Brown Obsessive Compulsive Scale. I. Development, use, and reliability. Arch Gen Psychiatry 1989; 46: 1006-11.

8. Delorme R, Bille A, Betancur C, et al.: Exploratory analysis of obsessive compulsive symptom dimensions in children and adolescents: a prospective follow-up study. BMC Psychiatry 2006; 6: 1

9. Flament MF, Whitaker A, Rapoport JL, et al.: Obsessive compulsive disorder in adolescence: an epidemiological study. J Am Acad Child Adolesc Psychiatry 1988; 27: 764-71.

10. Valleni-Basile LA, Garrison CZ, Jackson KL, et al.: Frequency of obsessive-compulsive disorder in a community sample of young adolescents. J Am Acad Child Adolesc Psychiatry 1994; 33: 782-91.

11. Kessler RC, Berglund P, Demler 0 , Jin R, Merikangas KR, Walters EE: Lifetime prevalence and age-of-onset distributions of DSM-IV disorders in the National Comorbidity Survey Replication. Arch Gen Psychiatry 2005; 62: 593-602.

12. Kessler RC, Chiu WT, Demler O, Merikangas KR, Walters EE: Prevalence, severity, and comorbidity of 12-month DSM-IV disorders in the National Comorbidity Survey Replication. Arch Gen Psychiatry 2005; 62: 617-27.

13. Delorme R, Golmard JL, Chabane N, et al.: Admixture analysis of age at onset in obsessive-compulsive disorder. Psychol Med 2005; 35: $237-43$.

14. Geller D, Biederman J, Jones J, et al.: Is juvenile obsessivecompulsive disorder a developmental subtype of the disorder? A review of the pediatric literature. J Am Acad Child Adolesc Psychiatry 1998; 37: 420-7.

15. Chabane N, Delorme R, Millet B, Mouren MC, Leboyer M, Pauls D: Early-onset obsessive-compulsive disorder: a subgroup with a specific clinical and familial pattern? J Child Psychol Psychiatry 2005; 46: 881-7

16. Walitza S, Scherag A, Renner TJ, et al.: Transmission disequilibrium studies in early onset of obsessive-compulsive disorder for polymorphisms in genes of the dopaminergic system. J Neural Transm 2008; 115: 1071-8.

17. Banaschewski T, Siniatchkin M, Uebel H, Rothenberger A: Zwangsphänomene bei Kindern mit Tic-Störung bzw. Aufmerksamkeitsdefizit-Hyperaktivitätsstörung. Z Kinder Jugendpsychiatr Psychother 2003; 31: 203-11.

18. Masi G, Millepiedi S, Mucci M, Bertini N, Pfanner C, Arcangeli F: Comorbidity of obsessive-compulsive disorder and attention-deficit/ hyperactivity disorder in referred children and adolescents. Compr Psychiatry 2006; 47: 42-7.

19. Leonard HL, Swedo SE, Lenane MC, et al.: A 2- to 7-year follow-up study of 54 obsessive-compulsive children and adolescents. Arch Gen Psychiatry 1993; 50: 429-39.

20. Walitza S, Zellmann H, Irblich B, et al.: Children and adolescents with obsessive-compulsive disorder and comorbid attention-deficit/ hyperactivity disorder: preliminary results of a prospective follow-up study. J Neural Transm 2008; 115: 187-90. 
21. Stewart SE, Geller DA, Jenike M, et al.: Long-term outcome of pediatric obsessive-compulsive disorder: a meta-analysis and qualitative review of the literature. Acta Psychiatr Scand 2004; 110: 4-13.

22. Thomsen PH, Jensen J: Obsessive-compulsive disorder: admission patterns and diagnostic stability. A case-register study. Acta Psychiatr Scand 1994; 90: 19-24.

23. Wewetzer C, Jans T, Muller B, et al.: Long-term outcome and prognosis of obsessive-compulsive disorder with onset in childhood or adolescence. Eur Child Adolesc Psychiatry 2001; 10: 37-46.

24. Zellmann $H$, Jans $T$, Irblich $B$, et al.: Kinder und Jugendliche mit Zwangsstörungen - eine prospektive Verlaufsstudie / Prospective follow-up study in early onset obsessive-compulsive disorder. Z Kinder Jugendpsychiatr Psychother 2009; 37: 173-82.

25. Zellmann $H$, Jans $T$, Irblich $B$, et al.: Der mittelfristige Verlauf von Zwangsstörungen mit Beginn im Kindes- und Jugendalter: Aspekte der psychosozialen Anpassung. Verhaltenstherapie \& Verhaltensmedizin 2008; 29: 336-51.

Corresponding author

Prof. Dr. med. Dipl. Psych. Susanne Walitza

Zentrum für Kinder- und Jugendpsychiatrie

Universität Zürich

Neumünsterallee 9

8032 Zürich, Switzerland

susanne.walitza@kjpdzh.ch

(2) For eReferences please refer to:

www.aerzteblatt-international.de/ref1111 


\title{
Obsessive-Compulsive Disorder in Children and Adolescents
}

\author{
by Susanne Walitza, Siebke Melfsen, Thomas Jans, Henrike Zellmann, \\ Christoph Wewetzer, and Andreas Warnke
}

\section{eREFERENCES}

e1. Valderhaug R, Ivarsson T: Functional impairment in clinical samples of Norwegian and Swedish children and adolescents with obsessive-compulsive disorder. Eur Child Adolesc Psychiatry $2005 ; 14: 164-73$

e2. Jans T, Wewetzer C, Muller B, et al.: Der Langzeitverlauf von Zwangsstörungen mit Beginn im Kindes- und Jugendalter: Psychosoziale Adaptation im Erwachsenenalter Zeitschrift Kinderund Jugendpsychiatrie und Psychotherapie 2001; 29: 25-35.

e3. Walitza S, Wendland JR, Gruenblatt E, et al.: Genetics of earlyonset obsessive-compulsive disorder. Eur Child Adolesc Psychiatry 2010; 19: 227-35

e4. van Grootheest DS, Cath DC, Beekman AT, Boomsma DI: Twin studies on obsessive-compulsive disorder: a review. Twin Res Hum Genet 2005; 8: 450-8.

e5. Kuhn J, Gründler TO, Lenartz D, Sturm V, Klosterkötter J, Huff W: Deep brain stimulation for psychiatric disorders. Dtsch Arztebl Int 2010; 107(7): 105-13.

e6. Arnold PD, Richter MA: Is obsessive-compulsive disorder an autoimmune disease? CMAJ 2001; 165: 1353-8.

e7. Fogel J: An epidemiological perspective of obsessive-compulsive disorder in children and adolescents. Can Child Adolesc Psychiatry Rev 2003; 12: 33-6.

e8. Snider LA, Lougee L, Slattery M, Grant P, Swedo SE: Antibiotic prophylaxis with azithromycin or penicillin for childhood-onset neuropsychiatric disorders. Biol Psychiatry 2005; 57: 788-92.

e9. Salkovskis PM: Obsessional-compulsive problems: a cognitivebehavioural analysis. Behav Res Ther 1985; 23: 571-83.

e10. Salkovskis PM: Cognitive-behavioural factors and the persistence of intrusive thoughts in obsessional problems. Behav Res Ther 1989; 27: 677-82; discussion 83-4.

e11. Freeman JB, Choate-Summers ML, Moore PS, et al: Cognitive behavioral treatment for young children with obsessive-compulsive disorder. Biol Psychiatry 2007; 61: 337-43. e12. Shalev I, Sulkowski ML, Geffken GR, Rickets EJ, Murphy TK, Storch EA: Long-term durability of cognitive behavioral therapy gains for pediatric obsessive-compulsive disorder. J Am Acad Child Adolesc Psychiatry 2009; 48: 766-7.

e13. Geller DA, Biederman J, Stewart SE, et al: Which SSRI? A meta-analysis of pharmacotherapy trials in pediatric obsessivecompulsive disorder. Am J Psychiatry 2003; 160: 1919-28.

e14. Gerlach M, Mehler-Wex C, Walitza S, Wewetzer C: Neuro-Psychopharmaka im Kindes- und Jugendalter. Grundlagen und Therapie. 2. Auflage. Wien: Springer 2009; 558.

e15. Wewetzer C, Walitza S: Neuro-Psychopharmaka im Kindes- und Jugendalter. In: Gerlach M, Mehler-Wex C, Walitza S, Warnke A, Wewetzer C ed, Neuro-Psychopharmaka im Kindes- und Jugendalter. 2. Auflage. Wien: Springer 2009: 507-12.

e16. Team-POTS: Cognitive-behavior therapy, sertraline, and their combination for children and adolescents with obsessivecompulsive disorder: the Pediatric OCD Treatment Study (POTS) randomized controlled trial. JAMA 2004; 292: 1969-76.

e17. O'Kearney RT, Anstey KJ, von Sanden C, Hunt A: Behavioural and cognitive behavioural therapy for obsessive compulsive disorder in children and adolescents. Cochrane Database of Systematic Reviews 2006, Issue 4: Art. No.:CD004856 DOI:10.1002/14651858.CD004856.pub2.The Cochrane Library 2010, Issue 1. 2006.

e18. Zaworka W, Hand I, Jauernig G, Luenenschloss K: Hamburger Zwangsinventar. Weinheim: Beltz; 1983.

e19. Klepsch R, Zaworka W, Hand I, Jauernig G: Hamburger Zwangsinventar. Weinheim: Beltz; 1993.

e20. Berg CZ, Rapoport JL, Flament M: The Leyton Obsessional Inventory - Child Version. J Am Acad Child Adolesc Psychiatry 1986; 25: 84-91.

e21. Goodman WK, Rasmussen SA, Riddle MA, Rapoport JL: CY-BOCS, dt. Bearbeitung 3. Rev. Steinausen HC. 1993. 